This item was submitted to Loughborough's Research Repository by the author.

Items in Figshare are protected by copyright, with all rights reserved, unless otherwise indicated.

\title{
Rapid process planning in CNC machining for rapid manufacturing applications
}

PLEASE CITE THE PUBLISHED VERSION

http://dx.doi.org/10.18178/ijmerr.6.2.118-121

\section{PUBLISHER}

(C) IJMERR

VERSION

VoR (Version of Record)

\section{PUBLISHER STATEMENT}

This work is made available according to the conditions of the Creative Commons Attribution-NonCommercialNoDerivatives 4.0 International (CC BY-NC-ND 4.0) licence. Full details of this licence are available at: https://creativecommons.org/licenses/by-nc-nd/4.0/

\section{LICENCE}

CC BY-NC-ND 4.0

\section{REPOSITORY RECORD}

Zahid, Muhammed Nafis Osman, Keith Case, and Darren Watts. 2019. "Rapid Process Planning in CNC Machining for Rapid Manufacturing Applications”. figshare. https://hdl.handle.net/2134/24346. 


\title{
Rapid Process Planning in CNC Machining for Rapid Manufacturing Applications
}

\author{
Muhammed Nafis Osman Zahid \\ Universiti Malaysia Pahang, Pahang, Malaysia \\ Email: nafis@ump.edu.my \\ Keith Case and Darren Watts \\ Loughborough University, Loughborough, United Kingdom \\ Email: $\{$ k.case, d.m.watts $\} @$ lboro.ac.uk
}

\begin{abstract}
Process planning is an important component in Computer Numerical Control (CNC) machining and directly influences the efficiency of cutting operations. However the planning task is highly dependent on the user's experience and is usually considered as a manual process. This paper seeks to remedy these problems by developing a tool to assist in executing the process planning task in CNC machining for rapid manufacturing applications. An advanced tool in Computer Aided Manufacturing (CAM) systems is exploited to record and generate programming code for instructions used to construct the operations. The code is then modified and integrated into the independent Graphical User Interface (GUI) to execute the process planning tasks within the CAM systems. Consequently, a customized program is developed and is capable of building the machining operations for all kinds of parts. The time spent for process planning is minimized and at the same time planning complexity that is highly depend on the user's experience is reduced.
\end{abstract}

Index Terms-process planning, rapid manufacturing, CNC machining

\section{INTRODUCTION}

A novel approach known as CNC Rapid Prototyping (CNC-RP) uses a subtractive process in Rapid Prototyping and Manufacturing (RP\&M) applications. The CNC-RP methodology utilizes a conventional 3-axis milling machine with two opposite 4th axis indexers and is able to machine parts by layer removal from various cutting directions [1]. The ndexable device employed in this process works to clamp and rotate the workpiece about one axis. Layers are removed from several orientations to reveal all surfaces of the part without refixturing [2]. Ultimately, this approach has enhanced the application of $\mathrm{CNC}$ milling machine to create complex shapes and features with minimum effort as in other rapid prototyping technologies. Fig. 1 illustrates the methodology employed in CNC-RP.

Manuscript received October 1, 2016; revised January 11, 2017.

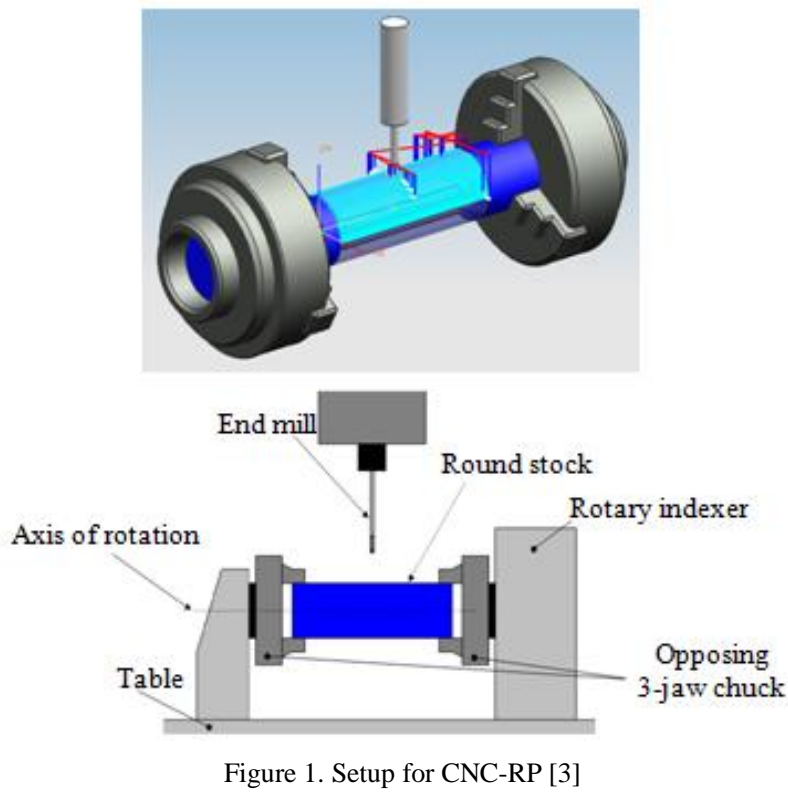

Process planning acts as a core and fundamental task in $\mathrm{CNC}$ machining processes. All the decisions executed at this stage directly influence the efficiency of cutting operations. This is one of the factors that makes some consider CNC process planning to be primarily a manual task [4]. Despite the new approaches proposed to enhance machining efficiency, process planning remains as a crucial component to assist the implementations. High quality machined parts can be achieved by implementing correct and reliable process steps in the planning phase [5]. The planning task in CNC machining is directly correlated to the time, skill and cost to machine discrete parts [6]. In contradiction with other RM methods, process planning for $\mathrm{CNC}$ machining is highly dependent on the experience of the CAM operator to develop an efficient machining plan [7]. However, recent developments in CAM technology have minimized the dependency on skilful machinists to handle machining process planning. Over the years, machining process planning has benefited from several research studies. Due to the strong needs of automation, integrated systems consisting of Computer Aided Design (CAD), CAM, Computer Automated Process Planning (CAPP) and 
production scheduling have been developed [8]. In order to enhance the communication tools in machining process planning, a new standard known as STEP-NC has been introduced to overcome weaknesses in G-codes (ISO 6983) [9]. It is considered that STEP-NC is more adaptable and interoperable. In addition, there have also been studies conducted to optimize process planning by automatically controlled cutting parameters [10].

Generally, the aforementioned findings aim to establish automation in machining process planning by focusing on different segments of the processing steps. This is particularly appropriate for 4th axis machining, where several attempts have been made to execute planning tasks in a semi or fully automatic manner [6], [11]. Basically, the developments are carried out through a commercial CAD/CAM interface and are particularly used in the application of 3-axis milling with an indexing device. With a small number of setups, the program will generate machining codes that assist cutting tools to machine from different orientations. Recently, further developments have been carried out to improve the methodology of CNC-RP and expand the applications in rapid manufacturing (CNC-RM) [12], [13]. These developments have minimized the machining time and broadened the selection of cutting orientations. The quality of machined parts has been enhanced by integrating different end mills tool in the processes. All these improvements are beneficial in the production stage of the parts. However, a fundamental issue lies in the planning stage which needs further improvement to work in a rapid environment. Some level of automation needs to be embedded in this stage to replace the manual and repetitive tasks. Constraining the planning problems is a key aspect in allowing the process to be automated [14], and several parameters can be standardized based on roughing and finishing operations. Recent developments in CAM systems permit integration with independent program files to execute specific functions, and with this ability, customized programs can be used to control the machining operations build-up during the planning stage. The method helps to directly establish rapid machining system for RM processes.

\section{METHODOLOGY}

Position CNC-RM machining processes execute cutting operations from different cutting directions that represent the orientations used to machine the parts. In each orientation, roughing and finishing operations form the shape of the part. Basically, in CAM systems, the instructions to construct these operations are quite similar and the differences only relate to tool sizes and a few cutting parameters. To visualize this, the development of cutting operations can be viewed as two levels of instructions as shown on

Fig. 2. The first level is a primary setup used to define the workpiece before constructing the operations. Then, the second level consists of the steps taken to build cutting operations in one particular orientation. Most of the time, several orientations are employed in CNC-RM processes. Therefore, the second level of operations is repeated with slightly different cutting parameters. This generates many repetitive instructions if the program is constructed manually. Hence, a practical and reliable method is required to handle the process planning tasks. The NX open API (Application Programming Interface) allows changes and customisation of NX instructions without manually running the applications in the interface. A tool known as Journaling is used to record, edit and replay NX sessions in executing certain tasks. The instructions are translated into a script file based on a common programming language (Visual Basic). In order to understand the relationship between the instructions and recorded codes, simple actions can be performed in NX while activating the journaling tools.

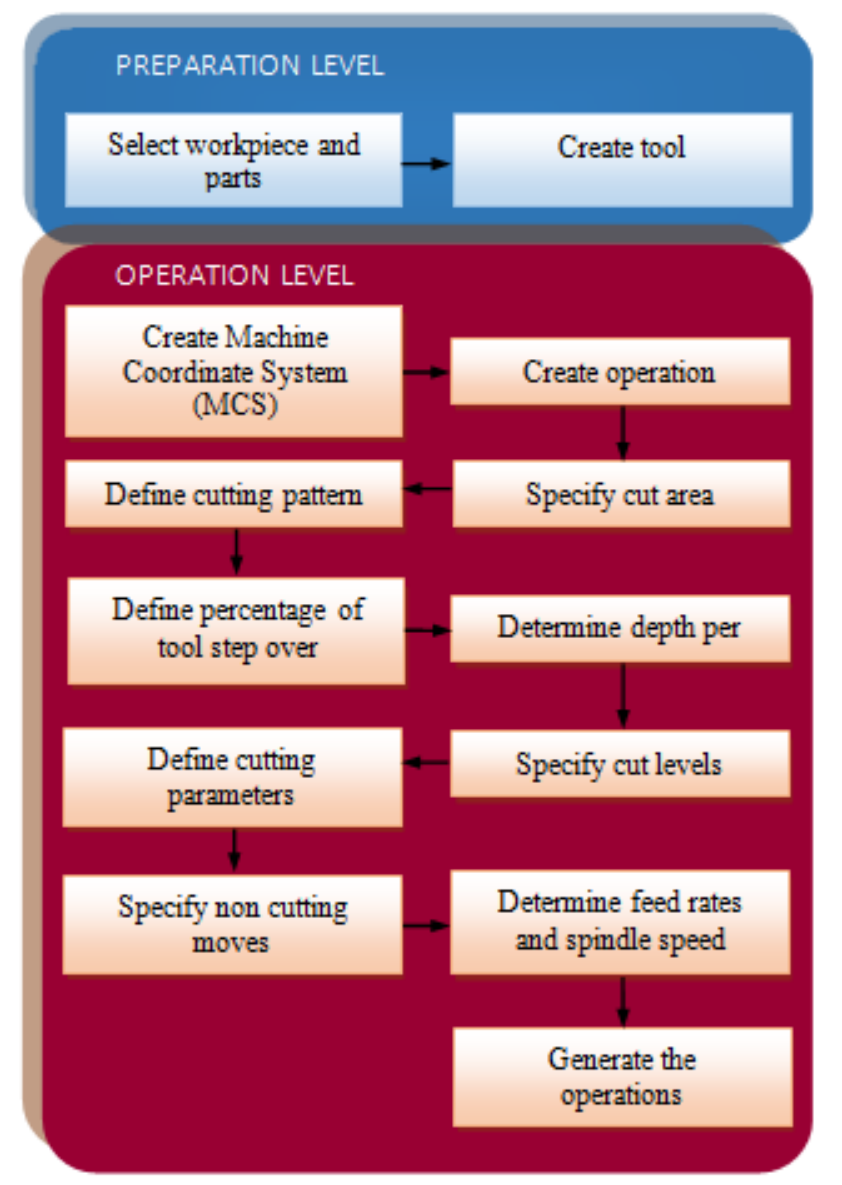

Figure 2. Instructions used to create milling operations

To develop the program codes, instructions at the preparation and operation levels are recorded through journaling. The codes are modified based on two approaches. Firstly, by identifying and grouping the tasks that used similar input. For example, the value of the workpiece diameter will be useful for several other tasks such as determining cutting depth and avoidance coordinates. Having this modification, the input parameters are shared with other tasks to generate operations efficiently. The second approach aims to remove the code stickiness by replacing the code that refers to specific part features with the pop out selection window. Eventually, these selection windows allow the user to select cutting areas on the models and makes the program adaptable to different components. 


\section{RAPID PROCESS PLANNING}

\section{A. Graphical User Interface (GUI)}

A customized program has been developed that is capable of building the machining operations for various cutting orientations. The program works on the NX platform. It also equipped with a simplified GUI to assist the user in process planning with fewer technical inputs. Once the program is initiated, a start-up window appears and the user is required to define the number of orientations. The next window allows the user to define several cutting parameters and orientation values. A series of machining operations including roughing and finishing processes are built up by pressing the 'Create operation' button. Prior to this, selection windows pop out to allow the user to define the cutting area, making the program adaptable to any kind of part. Finally, the "Generate machine codes" button will translate the operations into machining codes that depend on the type of CNC machine used.
1. Mechanical component

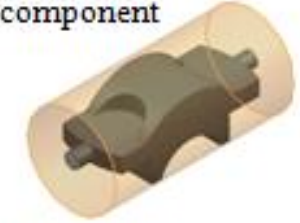

3. Prop mount

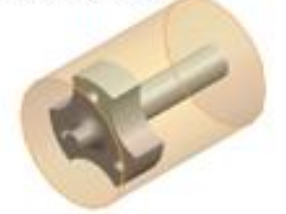

\section{Toothbrush stick}

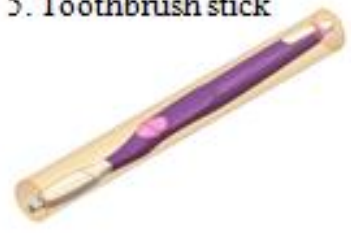

2. Propeller

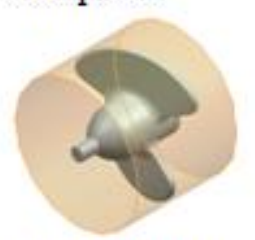

4. Shampoo bottle

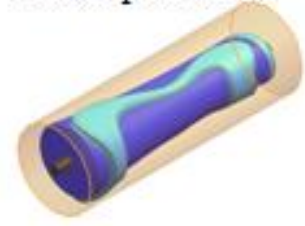

6. Earphone

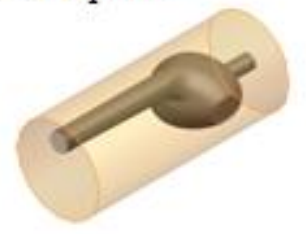

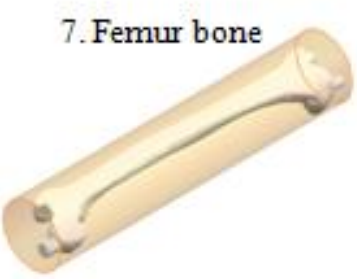

Figure 3. CAD models employed in process planning validation

\section{B. CNC-RM Machining Operations}

The rapid process planning program was validated by processing several CAD models [15] as illustrated in Fig. 3. The models selected varied in terms of shape and size, with each model requiring a different number of orientations and cutting parameters. Overall, the program manages to construct the machining operations correctly including both roughing and finishing operations. The data in Table I illustrates the efficiency of the program in assisting process planning in CNC-RM. The results can be described from several perspectives. First, the variety of components employed different numbers of orientations to completely produce the shapes. This reflects the number of operations performed for each model. Some models required up to 8 operations and the rest employed 6 or 7 operations including roughing and finishing. The planning time column indicates the time spent in process planning to build the machining operations. It shows the duration starting from activating the program, keying the parameters and proceeding with the selection windows until the whole operation sequence had been constructed. Generally, the times recorded for rapid process planning ranged between 2 and 8 minutes, and vary due to the complexity and shapes of the models.

TABLE I. RESULT OBTAINED FROM THE PROGRAM USED TO CONSTRUCT CNC-RM MACHINING OPERATIONS

\begin{tabular}{|c|c|c|c|c|c|}
\hline No. & $\begin{array}{c}\text { No. of } \\
\text { orientations }\end{array}$ & $\begin{array}{c}\text { No. of } \\
\text { operations }\end{array}$ & $\begin{array}{c}\text { Conventional } \\
\text { planning time } \\
\text { (min:sec) }\end{array}$ & $\begin{array}{c}\text { Rapid } \\
\text { process } \\
\text { planning } \\
\text { time } \\
(\mathrm{min}: \mathrm{sec})\end{array}$ & $\begin{array}{c}\text { Percentage } \\
\text { of time } \\
\text { reduction } \\
(\%)\end{array}$ \\
\hline 1 & 6 & 8 & $13: 18$ & $03: 24$ & 74 \\
\hline 2 & 8 & 8 & $16: 48$ & $07: 30$ & 55 \\
\hline 3 & 7 & 7 & $13: 29$ & $04: 15$ & 68 \\
\hline 4 & 8 & 8 & $15: 24$ & $05: 22$ & 65 \\
\hline 5 & 6 & 6 & $09: 54$ & $02: 07$ & 79 \\
\hline 6 & 7 & 7 & $11: 56$ & $02: 37$ & 78 \\
\hline 7 & 8 & 8 & $15: 41$ & $04: 00$ & 26 \\
\hline
\end{tabular}

The conventional planning time column indicates the time taken to construct the machining operations manually in the NX interface. If the part has 8 operations, each operation needs to be constructed manually and this involves considerable task repetition. The minimum time recorded was 9 minutes and extended up to 16 minutes for a user with only a basic knowledge of the CAM system. The results clearly indicate that the program developed for rapid process planning manages to reduce the time spent by up to $79 \%$ compared to conventional process planning. Standardizing and constraining the machining parameters has improved the process planning for CNC machines. Moreover, it has substantially reduced the processing time and expertise required to build the machining program. Indirectly, this result shows the effectiveness of the program designed to conduct the process planning tasks in CNC-RM.

\section{CONCLUSION}

This paper has discussed process planning for CNC machining in the application of rapid manufacturing. The research set out to develop a tool to assist in machining process planning that is considered to be a manual task and prone to human operator error and limited efficiency. The results have shown that the developed program manages to control and develop the machining operations 
in CNC-RM applications. Customized coding within the programs has worked effectively and is well-connected to prominent CAD software. Hence, a large number of machining operations can be controlled and performed with a minimum number of inputs. Considerably more work is needed to validate the approach with parts in real machining operations.

\section{ACKNOWLEDGMENT}

My deepest gratitude goes to Prof. Keith case and Dr Darren Watts for their assistance in this project. Apart of that, Thanks to Ministry of Education Malaysia and Universiti Malaysia Pahang for financially support the study.

\section{REFERENCES}

[1] M. Frank, S. B. Joshi, and R. A. Wysk, "CNC-RP: A technique for using CNC machining as a rapid prototyping tool in product/process development," in Proc. Industrial Engineering Research Conference, Orlando, FL. Citeseer, 2002.

[2] M. C. Frank, R. A. Wysk, and S. B. Joshi, "Determining setup orientations from the visibility of slice geometry for rapid computer numerically controlled machining," Journal of Manufacturing Science and Engineering, vol. 128, no. 1, pp. 228238, 2006.

[3] R. A. Wysk. (2008). Presentation Slides: A Look at the Past, Present and Future of Rapid Prototyping (RP). [Online]. Available: http://www.faim2008.org/FAIM-RP.ppt

[4] S. Anderberg, T. Beno, and L. Pejryd, "CNC machining process planning productivity - A qualitative survey," in Proc. International 3rd Swedish Production Symposium, Göteborg, Sweden, 2009.

[5] J. Zhao, D. H. Zhang, and Z. Y. Chang, "3D model based machining process planning," Advanced Materials Research, vol. 301-303, pp. 534-544, 2011.

[6] M. C. Frank, "Implementing rapid prototyping using CNC machining (CNC-RP) through a CAD/CAM interface," in Proc. Solid Freeform Fabrication Symposium, 2007.

[7] X. Xu, L. Wang, and S. T. Newman, "Computer-aided process planning-A critical review of recent developments and future trends," International Journal of Computer Integrated Manufacturing, vol. 24, no. 1, pp. 1-31, 2011

[8] Y. Nonaka, G. Erdős, T. Kis, A. Kovács, L. Monostori, T. Nakano, and J. Váncza, "Generating alternative process plans for complex parts," CIRP Annals-Manufacturing Technology, vol. 62, no. 1 , pp. $453-458,2013$.

[9] S. T. Newman, et al., "Strategic advantages of interoperability for global manufacturing using CNC technology," Robotics and Computer-Integrated Manufacturing, vol. 24, no. 6, pp. 699-708, 2008.

[10] F. Ridwan and X. Xu, "Advanced CNC system with in-process feed-rate optimization," Robotics and Computer-Integrated Manufacturing, vol. 29, no. 3, pp. 12-20, 2013.

[11] A. Agrawal, R. K. Soni, and N. Dwivedi, "Development of integrated CNC-RP system through CAD/CAM environment," International Journal of Mechanical and Production Engineering Research and Development, vol. 3, no. 5, pp. 1-10, 2013.
[12] M. N. O. Zahid, K. Case, and D. Watts, "Optimization of roughing operations in $\mathrm{CNC}$ machining for rapid manufacturing processes," Production \& Manufacturing Research, vol. 2, no. 1, pp. 519-529, 2014.

[13] M. N. O. Zahid, K. Case, and D. Watts, "Cutting tools in finishing operations for CNC rapid manufacturing processes: Experimental studies," International Journal of Mechanical, Aerospace, Industrial and Mechatronics Engineering, vol. 8, no. 6, pp. 1071-1075, 2014.

[14] D. Bourne, J. Corney, and S. K. Gupta, "Recent advances and future challenges in automated manufacturing planning," Journal of Computing and Information Science in Engineering, vol. 11, no. 2, pp. 021006-021006, 2011.

[15] GRABCAD. GrabCAD Workbench 2014-last update. [Online]. Available: http://grabcad.com/library

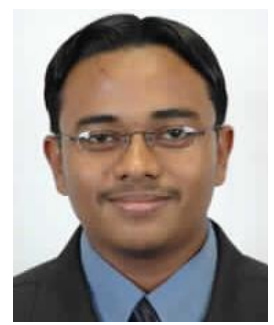

Muhammed Nafis Osman Zahid is Senior Lecturer in Faculty of Manufacturing Engineering Universiti Malaysia Pahang. He obtained BEng (Hons) in Mechanical (Manufacturing) Engineering from University of Technology Malaysia in 2006. He started his career as tutor in Universiti Malaysia Pahang. Then, he gained his MEngSc majoring Manufacturing Engineering and Management from University of New South Wales, Australia in 2008. In 2014, he was awarded a PhD from Loughborough University, United Kingdom. His work related to Computer Numerical Controlled (CNC) machining for the application of rapid manufacturing processes.

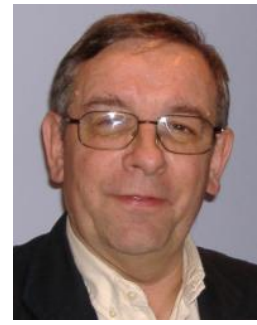

Keith Case is Professor of Computer Aided Engineering in Mechanical, Electrical and Manufacturing Engineering at Loughborough University and is a Chartered Engineer, Fellow of the Chartered Insti- tute of Ergonomics \& Human Factors and a Fellow of the British Computer Society. In 1994 he re- ceived the Ergonomics Society Ottob Edholm Award in recognition of his significant con tribution to the development and application of ergonomics, primarily in the area of digital human modelling.

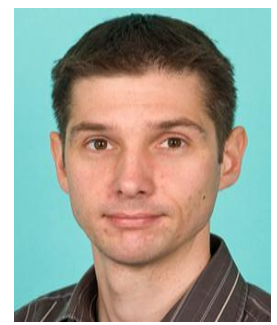

Darren Watts gained a BEng (Hons) in Mechanical Engineering and MSc (Eng) in Product Design \& Management from the University of Liverpool. He worked as a Mechanical Design Engineer for the Product Innovation \& Development Centre in Liverpool before taking up a Research Assistant post within the Engineering Department at the University of Liverpool in 2002. Darren then joined the Wolfson School of Mechanical and Manufacturing Engineering at Loughborough University as a University Teacher in CAD \& CAE in 2008. He was awarded a PhD in 2008 for his work $A$ Genetic Algorithm Based Topology Optimisation Approach for Exploiting Rapid Manufacturing's Design Freedom. Darren became a Fellow of the Higher Education Academy in 2010. In 2013 he was awarded an industrial secondement award by The Royal Academy of Engineering to join the CAE division of Majenta PLM Ltd for 6 months. 